RASĀYAN J. Chem.

Vol. 11 | No. 2 |915 - 928 | April - June | 2018

ISSN: 0974-1496 I e-ISSN: 0976-0083 | CODEN: RJCABP

http://www.rasayanjournal.com

http://www.rasayanjournal.co.in

\title{
GROWTH AND CHARACTERIZATION OF PROMISING NLO CRYSTAL: META NITROANILINE
}

\author{
K. Kumar ${ }^{\text {* }}$, K. Selvaraju ${ }^{1}$, P. Baskaran ${ }^{1}$, N. Senthilvelan ${ }^{2}$ and G. Rajarajan ${ }^{3,4}$ \\ ${ }^{1}$ PG and Research Department of Physics, Government Arts College, Ariyalur-621 113, India \\ ${ }^{2}$ Department of Physics, Arignar Anna Government Arts College, Attur-636 121, India \\ ${ }^{3}$ Department of Physics, Vidhya Mandhir Institute of Technology, Erode-638 052, India \\ ${ }^{4}$ VMIT Centre for Renewable Energy and Materials Science, Vidhya Mandhir Institute of \\ Technology, Erode-638 052, India \\ *E-mail: kumar.physics2011@gmail.com
}

\begin{abstract}
A good optical quality Meta Nitroaniline (mNA) single crystal was grown by slow evaporation method at room temperature. The grown crystals have been subjected to single crystal X-ray diffraction (XRD) to determine the unit cell dimensions. The Fourier Transform Infrared (FTIR) spectra have been recorded in the range $4000-400 \mathrm{~cm}^{-1}$. UV-Vis spectrum shows that the grown crystals have wide optical transparency in the entire visible region. The optical energy band gap of the grown crystal is found to be $4.3 \mathrm{eV}$. This high value of band gap energy and the lower cut-off wavelength of the crystal assert the suitability of the crystal for photonic and optical applications. The grown crystals were subjected to other characterizations such as microhardness, thermal and NLO studies and the results are discussed in detail.

Keywords: single crystals, optical characterization, thermal study, elastic stiffness constant, XRD, FTIR, mNA.

(C) RASĀYAN. All rights reserved
\end{abstract}

\section{INTRODUCTION}

These days, the nonlinear optics (NLO) field is getting a lot of attainment in science and technology since its progressions afford the foundation for the development of frequency up-converters and optical switches $^{1-3}$. Nonlinear optical materials capable of efficient second harmonic generation have been actively sought over the last three decades due to commercial importance. For this reason, scientists are constantly carrying out investigations towards the development of high-performance NLO materials with acceptable structural integrity in the solid-state. Hence, there is a special interest in exploring organic molecules in view of their ability to act as building blocks for the design of a widespread amount of molecular architectures ${ }^{4-7}$. Furthermore, the relatively good hyperpolarizability $(\beta)$ values of some of these organic molecules make them even more attractive candidates for the development of highly efficient NLO materials ${ }^{8,9}$. Hence recent search is concentrated on organic materials due to their large nonlinearity, high resistance to laser-induced damage, low angular sensitivity and good mechanical hardness.

Among organic compounds, nitroaniline derivatives have displayed large $\beta$ values due to the asymmetric charge distribution induced by the attachment of the electron-donating $\left(-\mathrm{NH}_{2}\right)$ and the electronwithdrawing $\left(-\mathrm{NO}_{2}\right)$ groups to the phenyl ring ${ }^{10-12}$. For instance, nitroaniline is a good example of a pushpull system due to the degree of conjugation induced by the location of the substituents $-\mathrm{NH}_{2}$ and $-\mathrm{NO}_{2}$ groups at para position to each other, which enhances it's $\beta$ value ${ }^{13}$. However, most of these compounds exhibit large molecular dipole moments, which leads to antiparallel molecular arrangements and consequently centrosymmetric crystal structures ${ }^{14}$. It is well known that the hydrogen bond plays an important role in controlling the molecular assemblies due to its directional characteristics ${ }^{15}$. For this reason, strong hydrogen bonds $(\mathrm{N}-\mathrm{H} / \mathrm{O}, \mathrm{OH} / \mathrm{O})$ are the most important elements in crystal engineering. Though, in the lack of these conventional hydrogen bonds, weaker interactions are answerable for crystal packing ${ }^{16}$.

Rasayan J. Chem., 11(2), 915-928(2018)

http://dx.doi.org/10.31788/RJC.2018.1121655 
In the instance of nitroaniline derivatives, it was found that they usually associate through intermolecular hydrogen bonds between the $-\mathrm{NH}_{2}$ and $-\mathrm{NO}_{2}$ groups giving the development of infinite polar chains, which can be useful for the design of efficient NLO materials ${ }^{17}$. Here in the present study due to the lack of work spotted in the literature encouraged us to make the above-mentioned studies on Meta Nitroaniline (mNA) crystals were grown and subjected to various characterizations and results are reported.

\section{EXPERIMENTAL}

The commercially existing Meta Nitroaniline (mNA) is purified by repetitive recrystallization procedure. The repeated recrystallized materials have been used for growth as charge material. Since Meta Nitroaniline (mNA) is soluble in Methanol and it is used as a solvent for crystal growth. The saturated solution of Meta Nitroaniline was obtained by dissolving the charge material into the solvent with continuous stirring of the solution using a magnetic stirrer at room temperature (305 K).

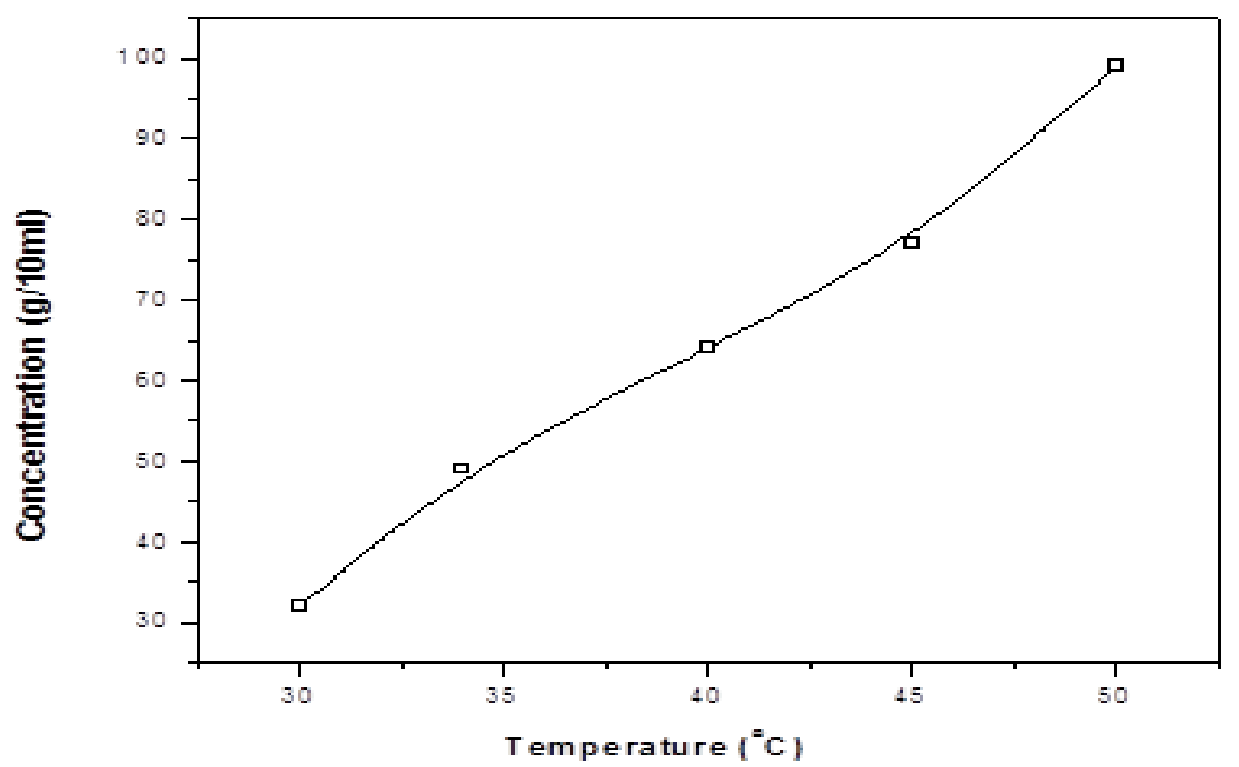

Fig.-1: Solubility Curve of mNA

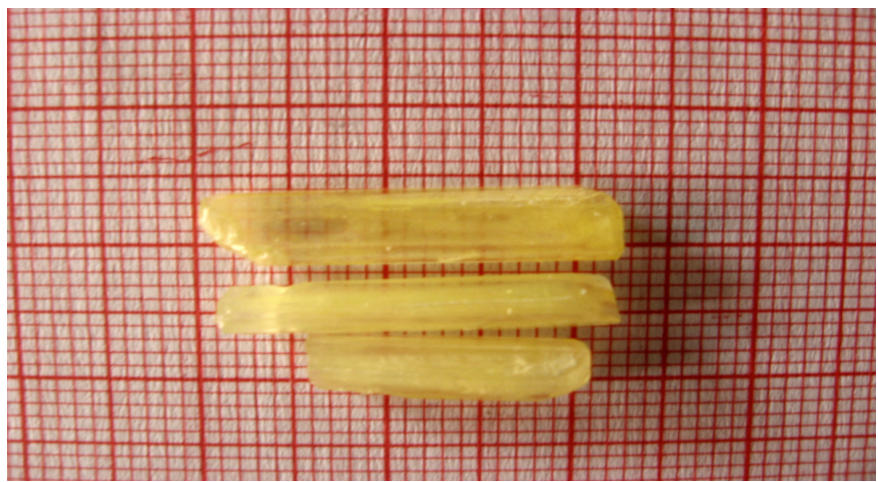

Fig.-2: Grown Crystal of mNA

On reaching saturation, the equilibrium concentration of the solute was determined by gravimetric analysis. The beaker containing the solution was optimally closed for controlled evaporation. Transparent yellow single crystals were obtained from the mother solution after a period of 15 days. Figure-1 shows the Solubility curves of mNA. Figure-2 shows the as-grown crystal of mNA with an optimized solution $\mathrm{pH}$ value of 3.7 . 


\section{Powder X-Ray Diffractions Studies}

\section{RESULTS AND DISCUSSION}

The structural properties of single crystals of mNA have been studied by X-Ray Powder diffraction technique. The X-Ray diffraction studies were carried out using SEIFERT diffractometer with $\mathrm{CuK} \alpha_{1}$ $(\lambda=1.5406 \AA)$ radiation. The powdered samples were scanned over the range of $10^{\circ}-50^{\circ}$ at a rate of $1^{\circ}$ per minute. From the powdered X-Ray data, various planes of reflections were indexed using XRDA 3.1 program and the lattice parameters were evaluated and agree with reported values ${ }^{18}$. The Powder X-ray diffraction pattern is shown in Figure 3. The crystallographic data are given in Table-1. Figure-4 represents the molecular packing of the mNA in the unit cell.

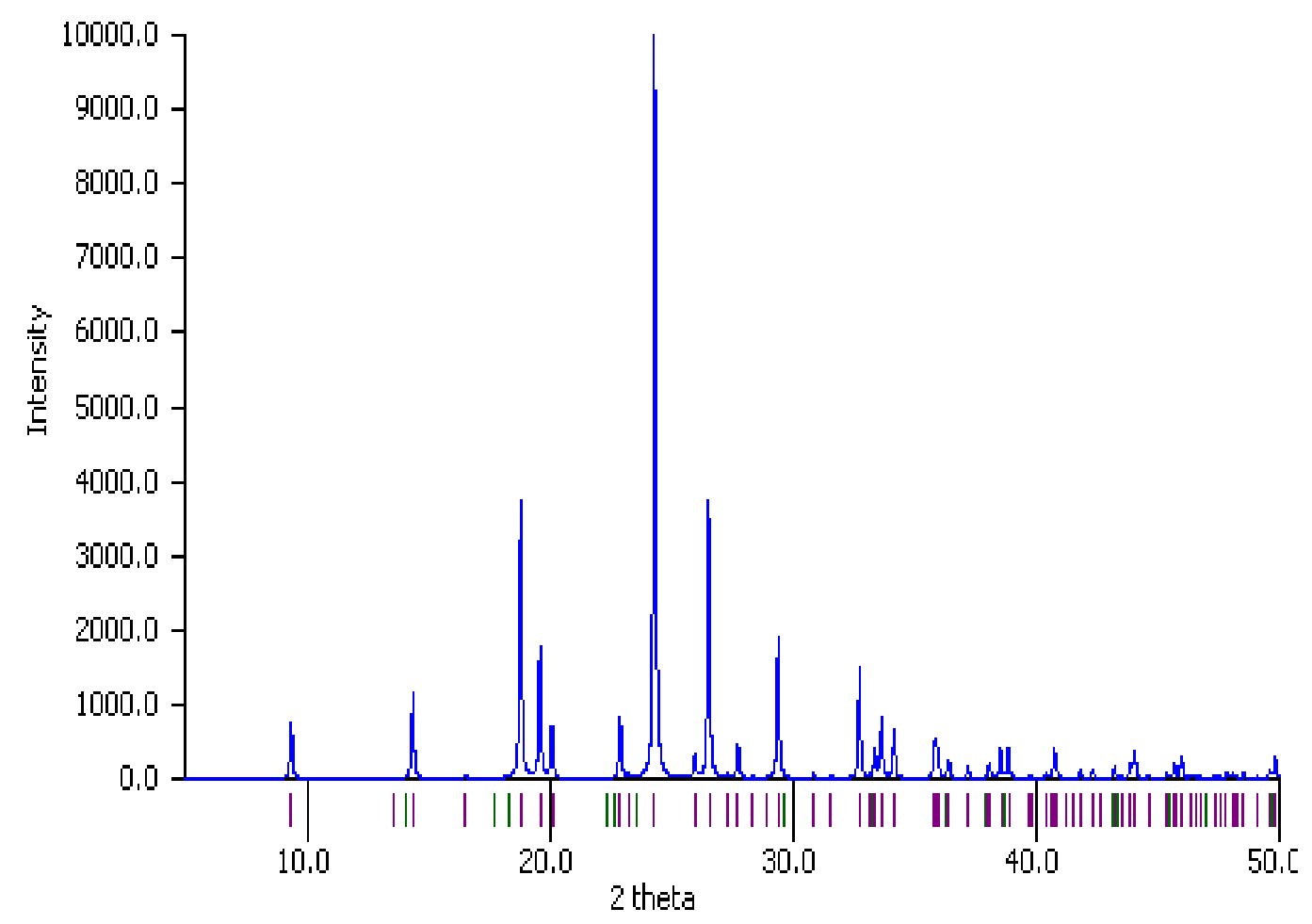

Fig.-3: The XRD pattern of mNA

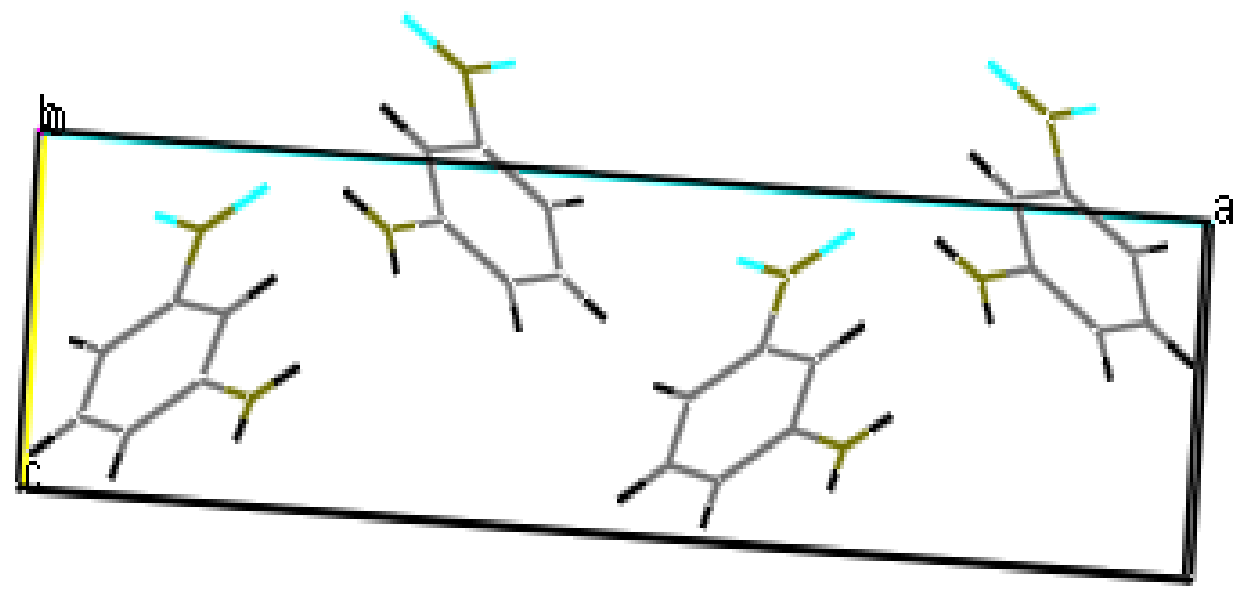

Fig.-4: Molecular packing of the mNA in the unit cell 
Table-1: Crystallographic Data of mNA

\begin{tabular}{c|c}
\hline Identification code & mNA \\
\hline Empirical formula & $\mathrm{C}_{6} \mathrm{H}_{6} \mathrm{~N}_{2} \mathrm{O}_{2}$ \\
\hline Formula weight & 138.1247 \\
\hline Crystal structure & Orthorhombic \\
\hline Space group & Pca2(1) \\
\hline \multicolumn{2}{|c}{ Cell parameters } \\
\hline $\mathrm{a}(\AA)$ & 18.873 \\
\hline $\mathrm{b}(\AA)$ & 6.5212 \\
\hline $\mathrm{c}(\AA)$ & 4.9980 \\
\hline$\alpha\left(^{\circ}\right)$ & 90.00 \\
\hline$\beta\left(^{\circ}\right)$ & 90.00 \\
\hline$\gamma\left(^{\circ}\right)$ & 90.00 \\
\hline Volume $(\AA)^{3}$ & 615.13 \\
\hline $\mathrm{Z}$ & 4 \\
\hline
\end{tabular}

\section{UV-Visible Transmittance Study}

The UV-Vis transmission spectrum of pure and mNA crystals was recorded in the range of 200-1100 nm and is shown in the Fig.-5. The instrument used was LAMBDA-35 UV-Vis spectrophotometer. From the spectrum, it is seen that the lower cut off wavelength of mNA was around $280 \mathrm{~nm}$. The spectrum further indicates that the crystal has a wide optical window from $280 \mathrm{~nm}$ to $1100 \mathrm{~nm}$.

The transparency in the entire visible region shows that this material is a best suitable candidate for optoelectronic application $^{19,20}$.

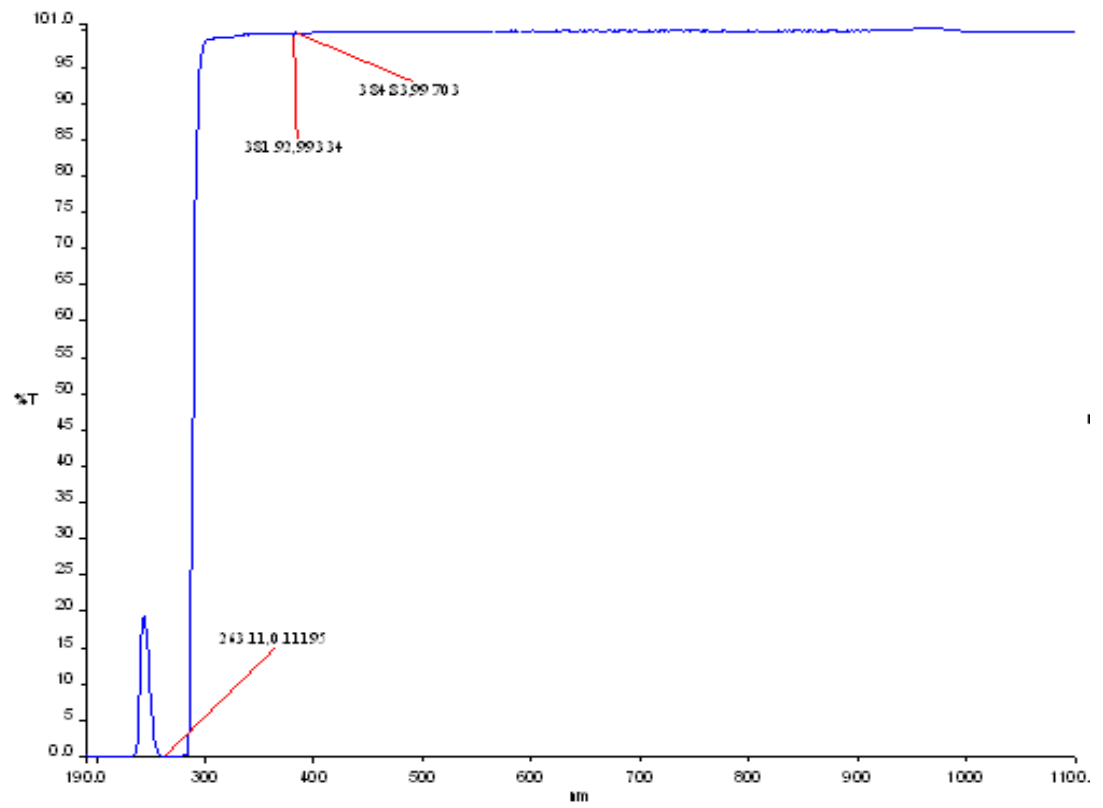

Fig.-5: UV-Vis Spectrum of mNA crystal

\section{Energy Band Gap}

The variant of $(\alpha h v)^{2}$ versus incident photon energy (hv) by means of the Tauc relation in the fundamental absorption region was plotted and is shown in Figure 6. The optical band gap energy (Eg) was estimated by extrapolation of the linear portion of the curve to a point $(\alpha h v)^{2}=0$. Using this method, the optical energy band gap of the crystal is found as $4.3 \mathrm{eV}$. This high value of band gap energy and the lower cutoff wavelength of the crystal affirm the suitability of the crystal for photonic and optical applications. 
RASĀYAN J. Chem.

Vol. 11 | No. 2 |915 - 928 | April - June | 2018

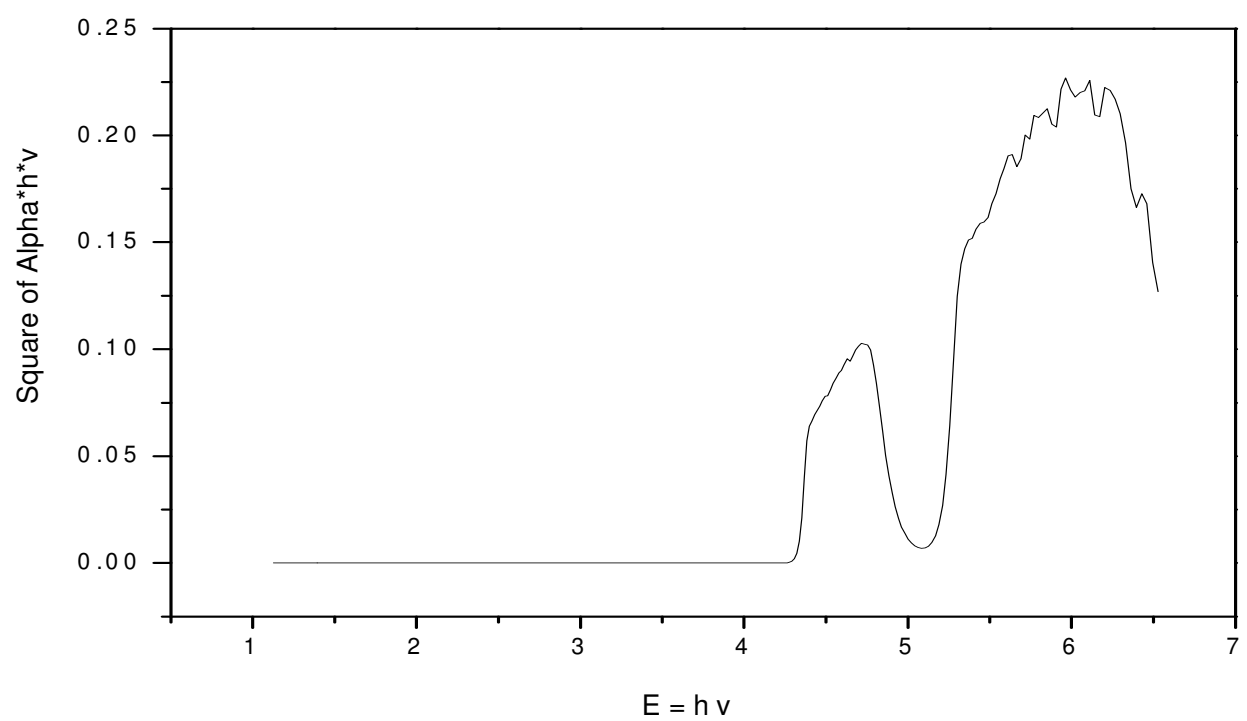

Fig.-6: The variation of $(\alpha h v)^{2}$ and incident photon energy $(h v)$ of mNA

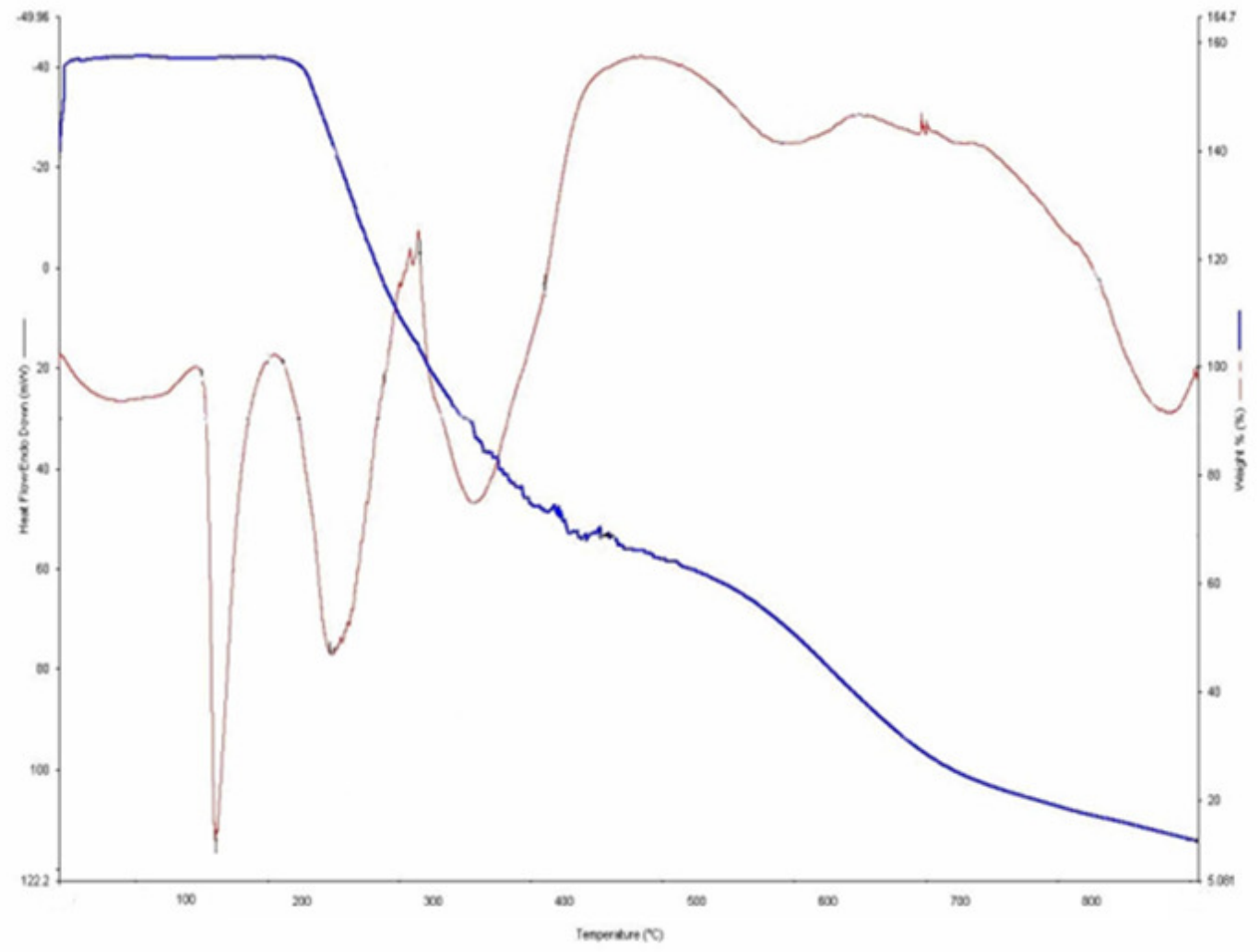

Fig.-7: TG and DTA Thermograms of mNA crystal

Thermal Analysis

The thermal analysis (TGA) study was carried out by using TAQ-500 analyzer at a heating rate of $25^{0}$ $\mathrm{C} / \mathrm{min}$ for temperature range 50 to $1000^{\circ}$ in nitrogen inert atmosphere to study the weight loss and thermal 
stability. The observed thermogram is reported in Figure 7. The crystal was stable up to the temperature of $114^{\circ} \mathrm{C}$. The DTA curve shows that this compound undertakes a series of endothermic peaks in a wide temperature range $\left(114-1000^{\circ} \mathrm{C}\right)$. The most important one appears at about $114^{\circ} \mathrm{C}$. It corresponds to a melting point. From $114^{\circ} \mathrm{C}$, the DTA curve shows a series of weak endothermic peaks characterized by an important weight loss observed on the TGA curve ${ }^{21}$. This thermal phenomenon is attributed to the degradation of the organic entity, well confirmed by the consistent residue of the crystal at the end of the experiment. The sharpness of the endothermic peak shows a good degree of crystallinity of the grown crystal $^{22}$. Thus the grown crystal is a best suitable material for NLO application.

\section{Vickers Hardness Test}

Vickers microhardness indentation test is used to characterize the hardness of the material. The hardness number can be evaluated by the knowledge of the load applied and the cross-sectional area of the depth of the impression. Smooth surfaces of as-grown crystals were chosen for the investigation. The Vicker's hardness value is calculated from the formula:

$$
\mathrm{H}_{\mathrm{v}}=1.8544 *\left(\mathrm{P} / \mathrm{d}^{2}\right) \mathrm{Kg} / \mathrm{mm}^{2}
$$

Where $\mathrm{P}$ is the applied load in $\mathrm{kg}$ and $\mathrm{d}$ is the average diagonal length in millimeters of the indented impressions.

In the present study, hardness was measured using Leitz-Wetzler hardness tester. Different loads were applied at a time of 10 seconds. The indentation marks were obtained and measured in terms of the diagonal length (d). Six trails were performed at each load to minimize the error. The plot of load (P) against Vicker's hardness $\left(\mathrm{H}_{\mathrm{v}}\right)$ is shown in Fig.-8. It is observed that the microhardness increases with the increase of load at lower values which can be attributed to the work hardening of the surface layers.

At higher loads beyond $100 \mathrm{gms}$, the microhardness shows a tendency to saturate ${ }^{23,24}$. Significant cracking occurs which may be due to the release of internal stresses generated locally by indentation. The relation connecting the applied load (P) and diagonal length (d) of the indenter is given by the Meyer Law. From Meyer's Law $\mathbf{P}=\mathbf{a d}^{\mathbf{n}}$ connecting the applied load (P) and diagonal length (d) of the indentation, the work hardening coefficient ' $n$ ' was calculated. Here ' $\mathbf{a}$ ' is a constant for a given material.

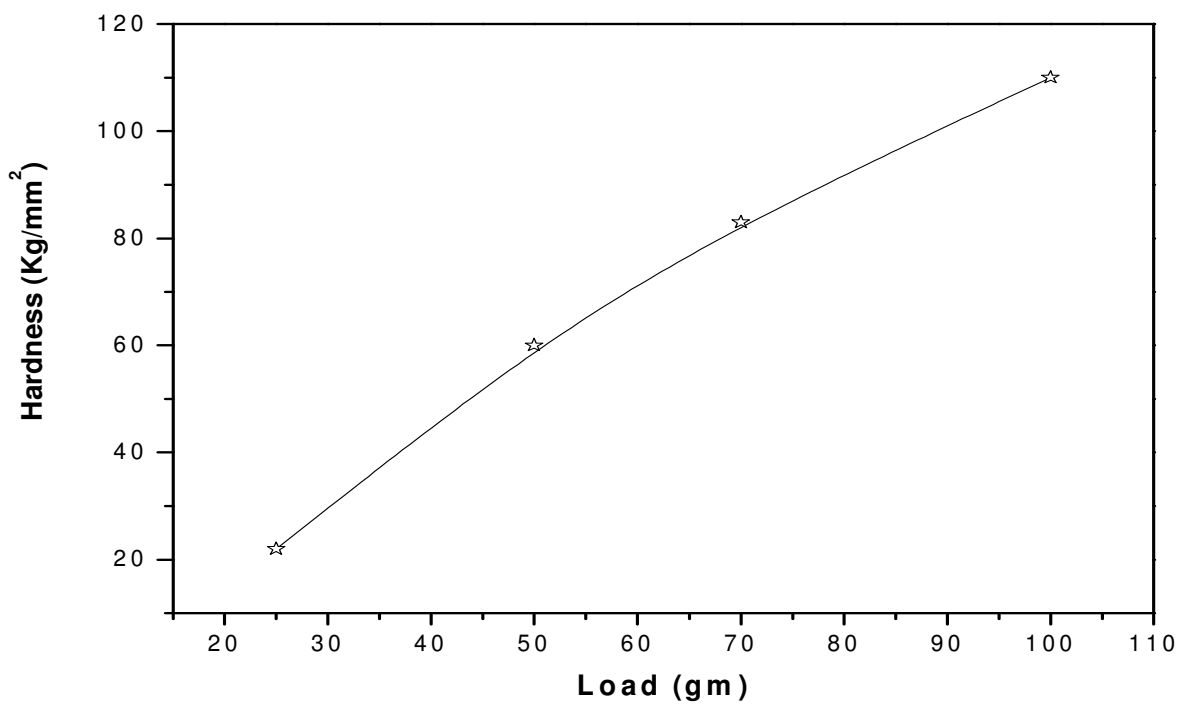

\section{Elastic Stiffness Constant}

Fig.-8: Vickers Hardness Vs load for mNA Crystals

The elastic stiffness constant $\left(\mathrm{C}_{11}\right)$ was calculated for different loads using Wooster's empirical formula ${ }^{25}$ $\mathrm{C}_{11}=\mathrm{H}_{\mathrm{v}}{ }^{7 / 4}$. The $\mathrm{C}_{11}$ values are shown in Table.2. These values give an idea about the tightness of bonding between neighboring atoms. The high value shows that the binding forces between the atoms were quite 
RASĀYAN J. Chem.

Vol. 11 | No. 2 |915 - 928 | April - June | 2018

strong. It was calculated for the loads from $25 \mathrm{gm}$ to $100 \mathrm{gm}$. The Plot of Hv versus Elastic Stiffness Constant for the title crystal is shown in Fig.-9.

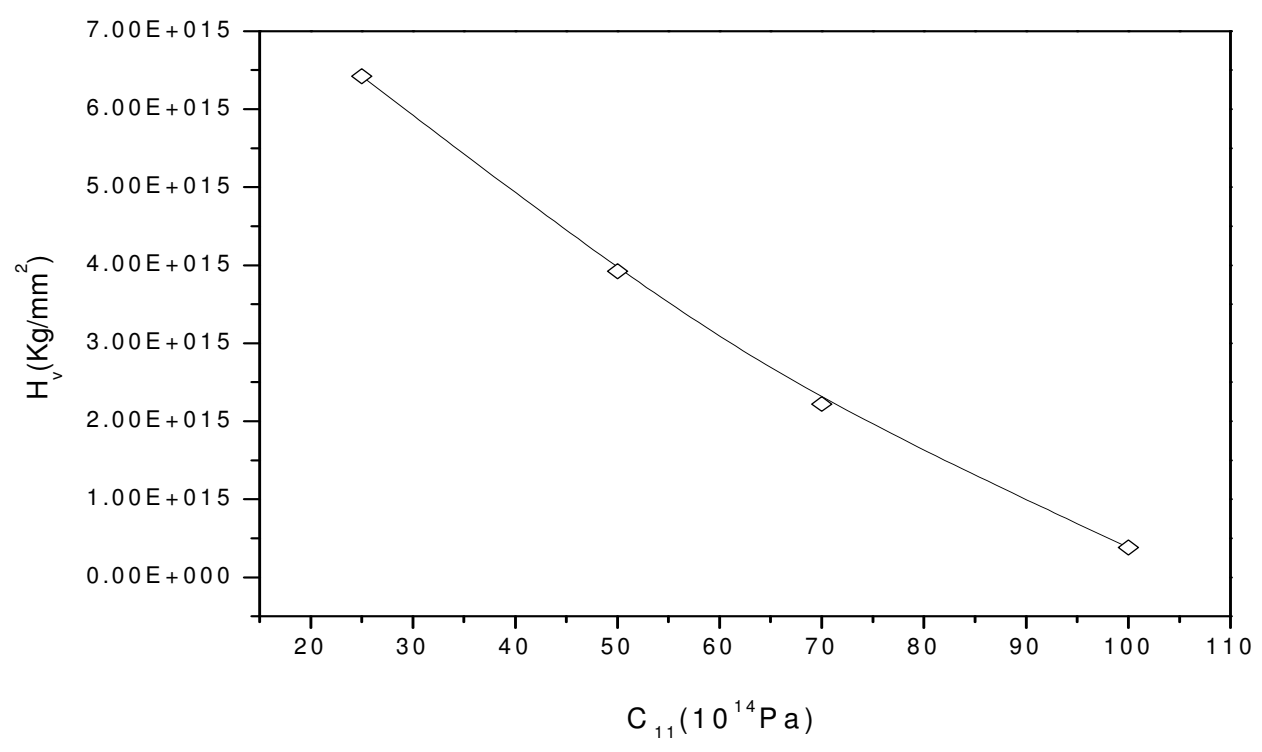

Fig.-9: Plot of $\mathrm{H}_{\mathrm{v} \text { versus }}$ Load of Elastic Stiffness Constant

Table-2: Elastic Stiffness Constant

\begin{tabular}{c|c}
\hline Load $(\mathrm{g})$ & $\mathrm{C}_{11}\left(10^{14} \mathrm{~Pa}\right)$ \\
\hline 25 & 64.2093 \\
\hline 50 & 39.2236 \\
\hline 70 & 22.2293 \\
\hline 100 & 3.8406 \\
\hline
\end{tabular}

\section{Dielectric Studies}

The frequency dependent measurements of capacitance, $\mathrm{C}$, and tan $\mathrm{d}$, were obtained using a computer controlled LCR meter N4L Numetric QPSM 1735 instrument. The dielectric constant of a material is generally composed of four types of contributions, viz. ionic, electronic, orientational and space charge polarization. All of these may be active at low frequencies. The nature of variations of dielectric constant with frequency and temperature indicates the type of contributions that are present in them. The dipolar orientational effect can be seen in some materials at high frequencies and ionic and electronic polarizations below $10^{3} \mathrm{~Hz}$. The large value of $\varepsilon_{\mathrm{r}}$ at low frequency and at low temperature is due to the presence of space charge polarization, which depends on the purity and perfection of the sample ${ }^{26}$. Figure-10 shows the variation of dielectric constant with frequency measured at room temperature for the mNA. The dielectric constant is a maximum at low frequency and decreases with increasing of frequency for the crystals. The increase in the dielectric constant at low frequency is attributed to space-charge polarization.

\section{SEM Studies}

Chemical analysis and morphological studies were carried out using scanning electron microscopy (SEM Model JSM 840A $)^{27}$. Figure-11 depicts the SEM image of the crystal. It shows some darker and brighter uneven areas. This might be due to solvent inclusions, which is most commonly observed in solution growth. Interesting features of surface morphologies are observed in SEM, actually exhibits stepped structure. Variations in step directions and the appearance of wider steps could be attributed to the general roughness/grain boundary. 


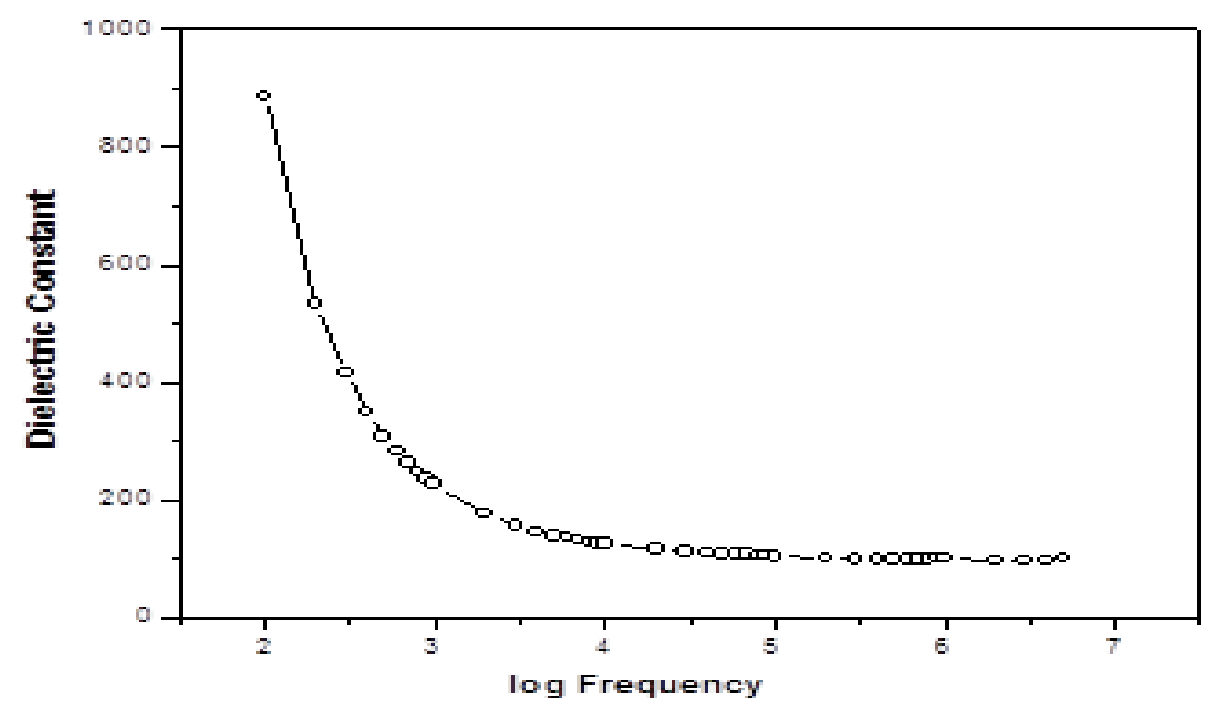

Fig.-10: Variation of Dielectric Constant with Frequency for mNA

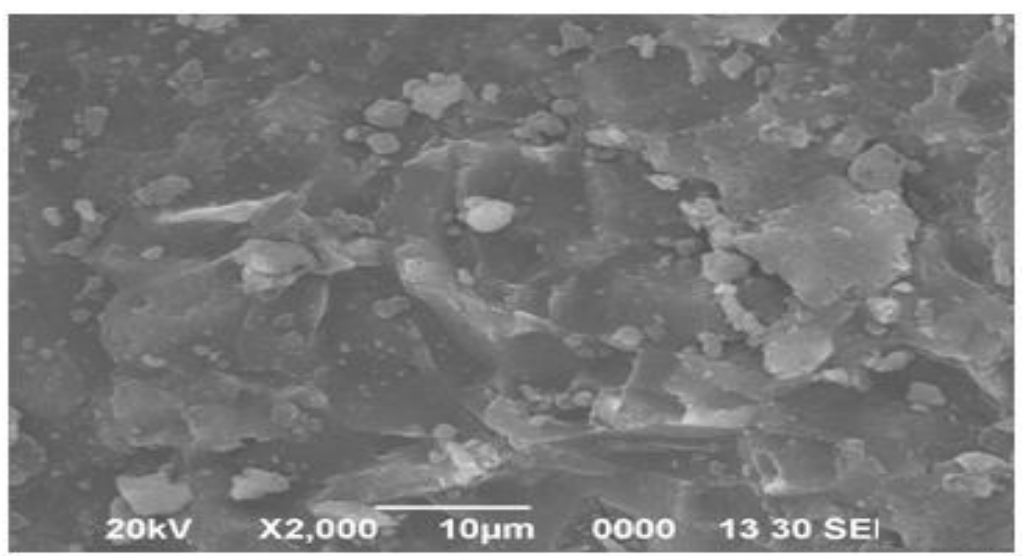

\section{SHG Efficiency Measurement}

Fig.-11: The SEM Image of the Crystal

The grown crystals were subjected to the NLO study to measure the efficiency with respect to Meta Nitroaniline. The SHG property of a grown crystal was tested by the Kurtz and Perry powder method. The optical signal generated from the sample was converted into an electrical signal and was measured using an oscilloscope. The measured outputs for Meta Nitroaniline were tabulated in Table-3.

Table-3: SHG efficiency measurement

\begin{tabular}{c|c|c|c|c}
\hline \multirow{2}{*}{ Input power $(\mathrm{mW})$} & \multicolumn{2}{|c|}{ Output power $(\mathrm{mW})$} & \multicolumn{2}{c}{ SHG conversion efficiency (\%) } \\
\cline { 2 - 5 } & KDP & mNA & KDP & mNA \\
\hline 285 & 190 & 210 & 67.0 & 73.0 \\
\hline 468 & 230 & 250 & 49.0 & 53.0 \\
\hline 688 & 320 & 320 & 47.0 & 52.0 \\
\hline 830 & 370 & 385 & 41.0 & 46.0 \\
\hline
\end{tabular}

\section{FTIR Measurements}

The room temperature Fourier transform infrared spectrum of mNA is shown in Fig.-12 and it was recorded in the region $400-4000 \mathrm{~cm}^{-1}$ at a resolution of $4 \mathrm{~cm}^{-1}$ using Perkin Elmer Fourier transform Infrared Spectrophotometer, model SPECTRUM RX1, using KBr pellets containing a fine mNA powder obtained from the grown single crystals, equipped with a $\mathrm{LiTaO}_{3}$ detector, a $\mathrm{KBr}$ beam splitter, $\mathrm{He}-\mathrm{Ne}$ 
Laser source and boxcar apodization used for 250 averaged interferograms collected for both the sample and the background.

The present vibrational spectroscopic study was carried out with a view to obtaining an insight into the structural aspects of optical nonlinearity of crystals ${ }^{28,29}$. In order to understand the existence of bonding nature of the materials, the present study has been undertaken. Thus the molecular structure of the synthesized compound was confirmed by the spectral analysis. The observed wave numbers, relative intensities obtained from the recorded spectra and the assignments proposed for the title nonlinear optical crystal is given in Table-4. The assignments of bands observed in the vibrational spectrum are an essential step for solving the structural and chemical problem.

Table-4: The bands observed in FTIR and its assignments

\begin{tabular}{|c|c|}
\hline $\begin{array}{c}\text { FTIR } \\
\text { Wavelength }\end{array}$ & Assignments \\
\hline 3778 & $\mathrm{NH}_{2}-$ Asymmetric Bending \\
\hline 3407 & $\mathrm{NH}_{2}-$ Asymmetric Bending \\
\hline 3124 & $\mathrm{NH}_{2}-$ Asymmetric Bending \\
\hline 3032 & $\mathrm{NH}_{2}-$ Asymmetric Bending \\
\hline 2920 & $\mathrm{NH}_{2}$-symmetric Stretching \\
\hline 2819 & $\mathrm{NH}_{2}$-symmetric Stretching \\
\hline 2701 & $\mathrm{NH}_{2}-$ Asymmetric Bending \\
\hline 2612 & $\mathrm{NH}_{2}-$ Asymmetric Bending \\
\hline 2276 & C-H Stretching \\
\hline 1950 & C-C Stretching \\
\hline 1825 & C-N Asymmetric Stretching \\
\hline 1594 & $\mathrm{C}=\mathrm{C}$ aromatic stretching \\
\hline 1486 & C-N Asymmetric Stretching \\
\hline 1444 & C-N Asymmetric Stretching \\
\hline 1324 & CN stretching \\
\hline 1179 & Ring in-plane bending, $\mathrm{CH}$ in-plane bending \\
\hline 1101 & $\mathrm{CH}$ in-plane bending \\
\hline 1055 & Ring in-plane bending, $\mathrm{C}-\mathrm{O}$ stretching \\
\hline 933 & $\mathrm{C}-\mathrm{C}$ stretching \\
\hline 892 & C-H out of plane bending \\
\hline 836 & C-H Ring Puckering \\
\hline 756 & C-N symmetric Stretching \\
\hline 657 & Ring in-plane bending, C-C Stretching \\
\hline 615 & C-H deformation \\
\hline
\end{tabular}

\section{Photoluminescence Studies}

Photoluminescence (PL) measurement of mNA is taken at room temperature with $20 \mathrm{~mW}, 633 \mathrm{~nm} \mathrm{He}-\mathrm{Ne}$ laser is used for the excitation energy and shown in Fig.-13. A strong emission peak is observed from the spectrum at $355 \mathrm{~nm}$. This reveals that the grown crystal has a green emission property. This reveals that the grown crystal has a green emission property and also this strong peak indicates there may be the presence of intrinsic defects in the forbidden band region ${ }^{30}$.

\section{Hyper Polarizability Calculation}

For calculating the hyperpolarizability, the optimization has been carried out in the unrestricted open-shell Hartree-Fock level. The geometries are fully optimized without any constraint with the help of analytical gradient procedure implemented within Gaussian $03 \mathrm{~W}$ program $^{31}$. The electric dipole moment and dispersion-free first-order hyperpolarizability are calculated using finite field method. The finite field method offers a straightforward approach to the calculation of hyperpolarizability ${ }^{32}$. The 3-21(d,p) basis 
set gives remarkably good geometries for such a small basis set and in fact it is used for the geometry optimization of some high accuracy energy methods.

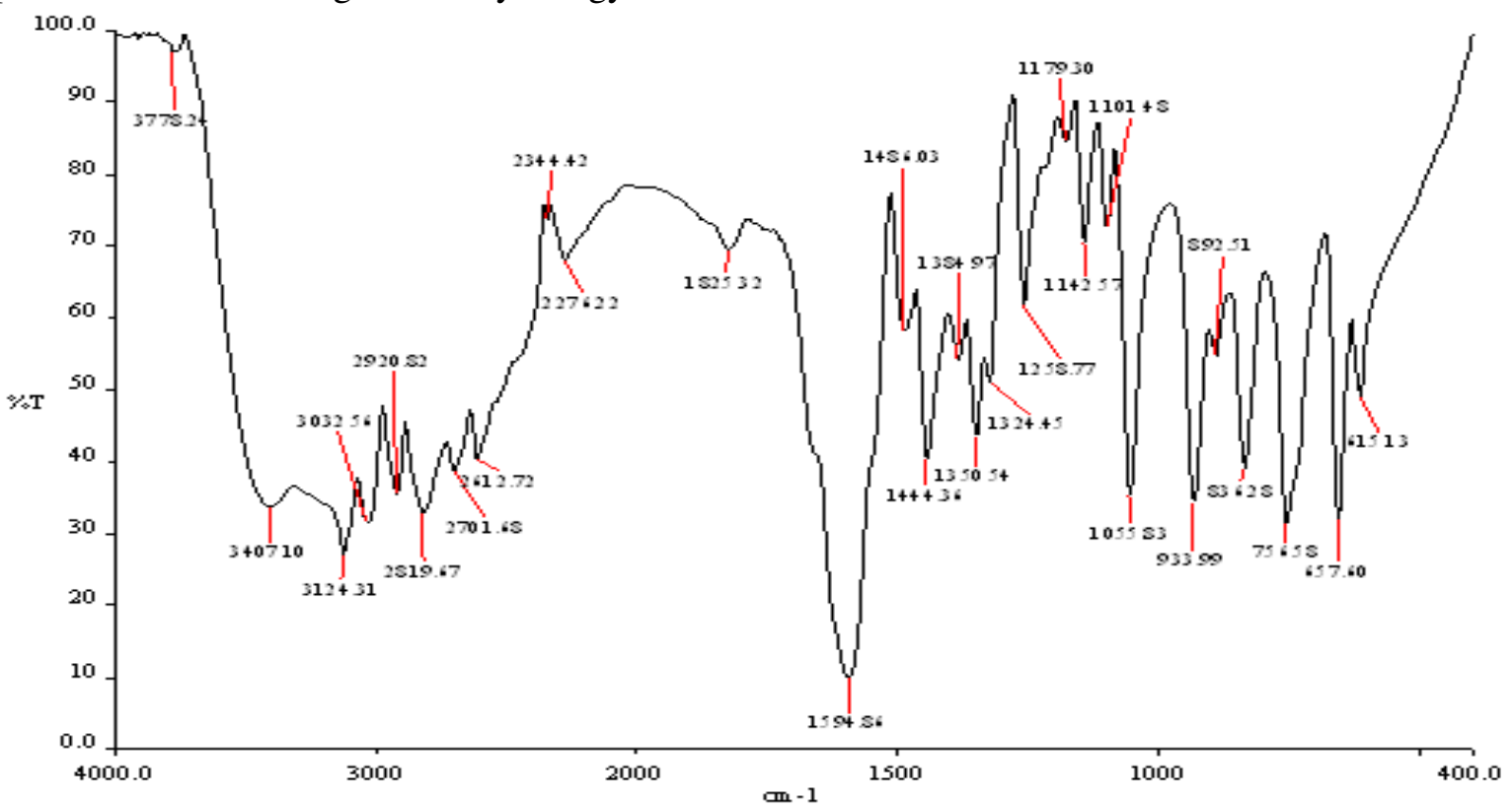

Fig.-12: FTIR spectrum of mNA

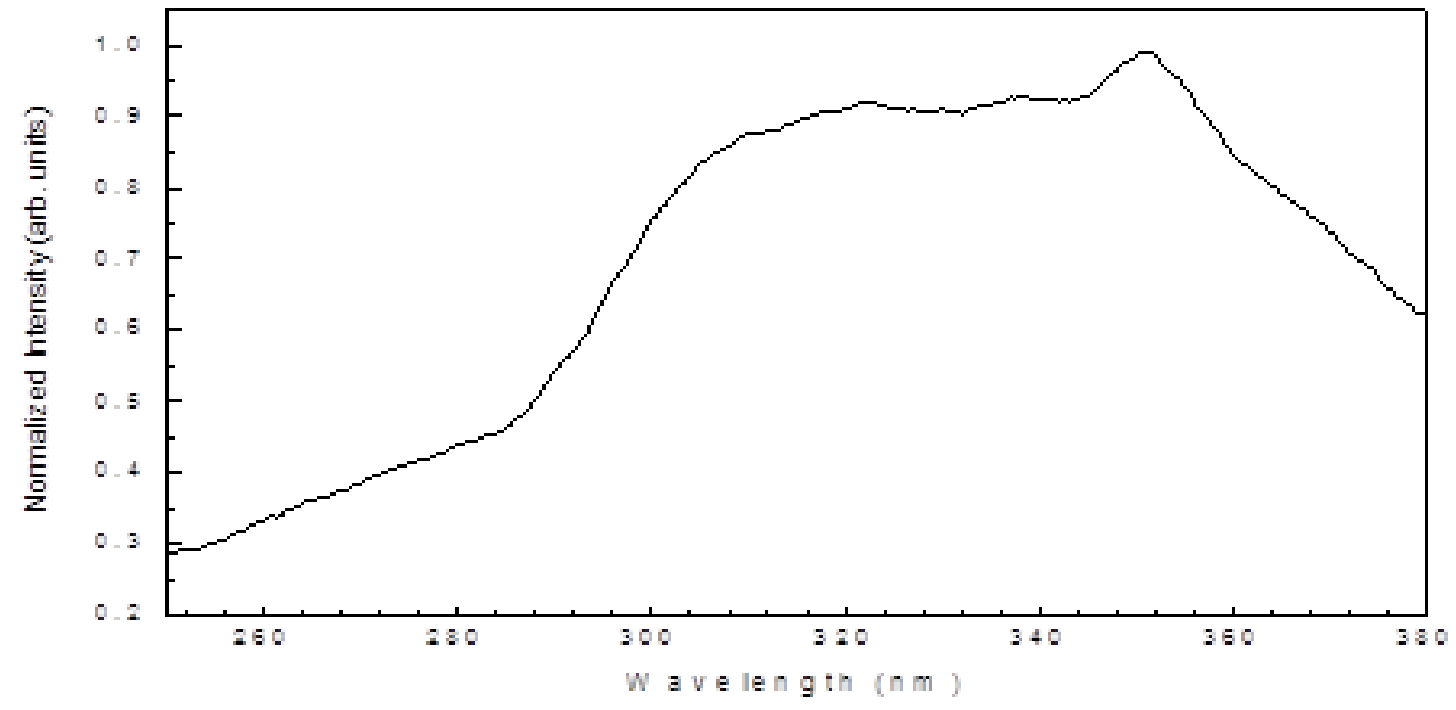

Fig.-13: Photoluminescence Spectrum of Growth mNa Crystal

The nonlinear properties of an isolated molecule in an electric field $\mathrm{E}_{\mathrm{i}}(\omega)$ can be represented by the Taylor expansion of the total dipole moment mi induced by the field is taken at zero fields, Dipole moment:

$$
\mu_{\mathrm{i}}=-\left[\frac{\partial^{2} E}{\partial F_{i} \partial F_{j}}\right]_{0}
$$

Components of polarizability tensor:

$$
\alpha_{\mathrm{ij}}=-\left[\frac{\partial E}{\partial F_{i}}\right]_{0}
$$


Components of hyperpolarizability tensor:

$$
\beta_{\mathrm{ijk}}=-\left[\frac{\partial^{3} E}{\partial F_{i} \partial F_{j} \partial F_{k}}\right]_{0}
$$

These components are to be distorted by an external electric field. The value of total static polarizability and hyperpolarizability are obtained from the following equation,

$$
\beta_{\mathrm{tot}}=\left[\left(\beta_{\mathrm{xxx}}+\beta_{\mathrm{xyy}}+\beta_{\mathrm{xzz}}\right)^{2}+\left(\beta_{\mathrm{yyy}}+\beta_{\mathrm{yzz}}+\beta_{\mathrm{yxx}}\right)^{2}+\left(\beta_{\mathrm{zzz}}+\beta_{\mathrm{zxx}}+\beta_{\mathrm{zyy}}\right)^{2}\right]^{1 / 2}
$$

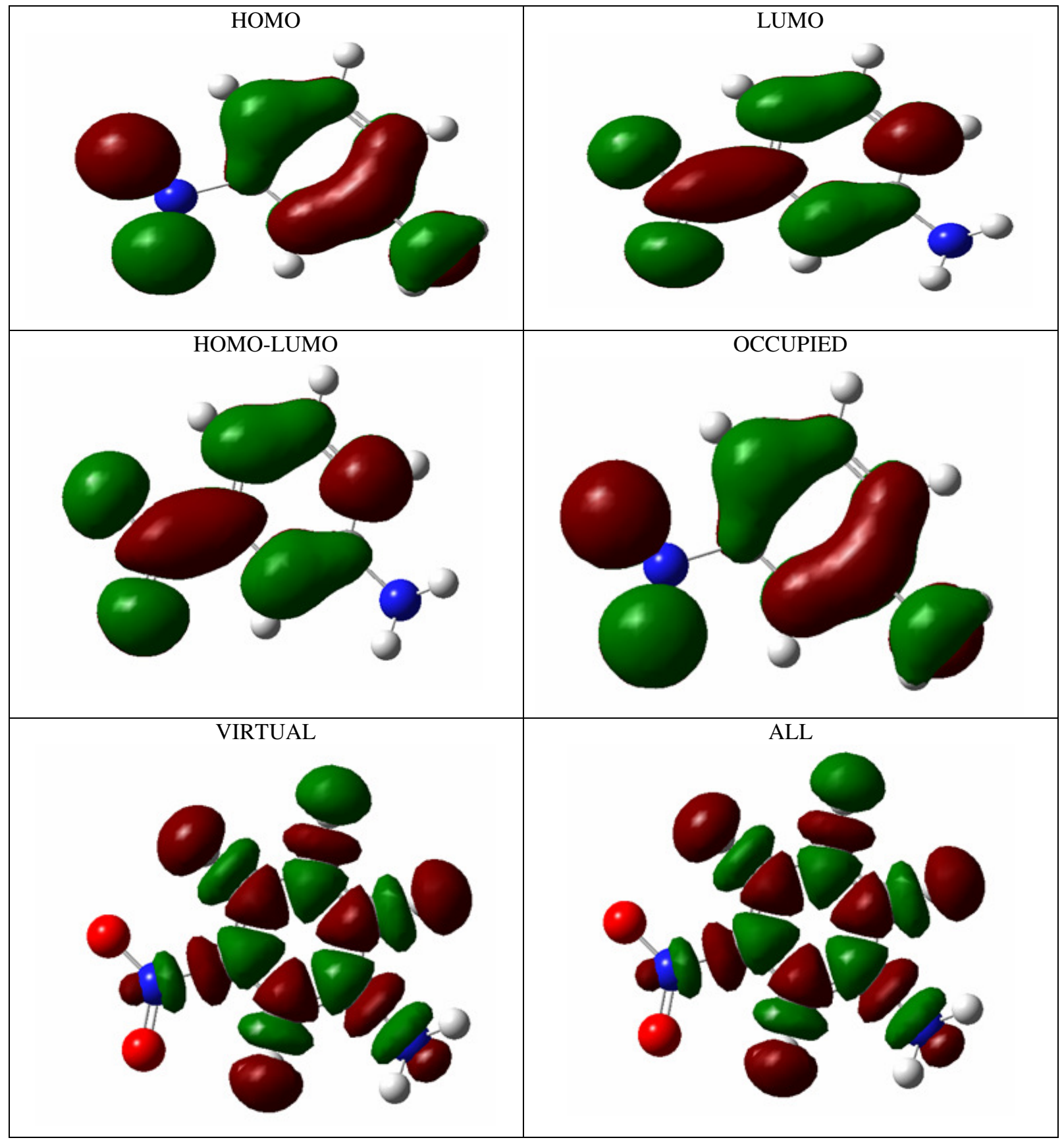

Fig.-14: Molecule orbital of Meta Nitroaniline

In the presence of an applied electric field, first-order hyperpolarizability is a third rank tensor that can be described by a $3 \times 3 \times 3$ matrix. The components of the $3 \mathrm{D}$ matrix can be reduced to 10 components 
because of the Kleinman symmetry ${ }^{33}$. The matrix can be given in the lower tetrahedral format. It is obvious that the lower part of the $3 \times 3 \times 3$ matrix is tetrahedral. The calculation of NLO properties with high accuracy is challenging and requires consideration of many different issues. Computational techniques are becoming valuable in designing, modeling and screening novel NLO materials. The calculated value of hyperpolarizability for the title compound is $0.402499 \times 10^{-30} \mathrm{esu}$, which is nearly 2 times that of urea $\left(0.1947 \times 10-^{30} \mathrm{esu}\right)$. The calculated values of dipole moment and hyperpolarizability values are tabulated in Table-5. The $\beta_{\mathrm{zxx}}$ direction shows the biggest value of hyperpolarizability which insists that the delocalization of electron cloud is more that direction than other directions.

Figure-14 shows the highest occupied molecule orbital (HOMO) and lowest unoccupied molecule orbital (LUMO) of Meta Nitroaniline. There is an inverse relationship between hyperpolarizability and HOMO-LUMO.

$$
\begin{gathered}
\text { HOMO energy }=-0.266 \text { a.u } \\
\text { LUMO energy }=0.169 \text { a.u } \\
\text { HOMO-LUMO energy gap }=0.435 \text { a.u }
\end{gathered}
$$

Table-5: The dipole moment $(\mu)$ and first-order hyperpolarizability $(\beta)$ of mNA derived from DFT calculations

\begin{tabular}{c|l}
\hline$\beta_{\mathrm{xxx}}$ & 0.46927 \\
\hline$\beta_{\mathrm{xxy}}$ & -0.11436 \\
\hline$\beta_{\mathrm{xyy}}$ & -0.27422 \\
\hline$\beta_{\mathrm{yyy}}$ & -0.00713 \\
\hline$\beta_{\mathrm{zxx}}$ & 0.205357 \\
\hline$\beta_{\mathrm{xyz}}$ & 0.072191 \\
\hline$\beta_{\mathrm{zyy}}$ & -0.15792 \\
\hline$\beta_{\mathrm{xzz}}$ & 0.155044 \\
\hline$\beta_{\mathrm{yzz}}$ & 0.129833 \\
\hline$\beta_{\mathrm{zzz}}$ & 0.15098 \\
\hline$\beta_{\mathrm{total}}$ & 0.402499 \\
\hline$\mu_{\mathrm{x}}$ & 0.02525878 \\
\hline$\mu_{\mathrm{y}}$ & $6.1127 \mathrm{E}-05$ \\
\hline$\mu_{z}$ & 0.00874343 \\
\hline$\mu$ & 0.18456254 \\
\hline$\beta$ &
\end{tabular}

Dipole moment $(\mu)$ in Debye, hyperpolarizibility $\beta(-2 \omega ; \omega, \omega) 10^{-30}$ esu.

\section{CONCLUSION}

The good optical quality Meta Nitroaniline (mNA) single crystals were grown by solution growth method at room temperature. The lattice parameters were found by single crystal XRD technique. From the UVVis spectrum, it is seen that the lower cut off wavelength of mNA were around $280 \mathrm{~nm}$ and its transparency in the entire visible region shows that this material is a best suitable candidate for optoelectronic application. The optical energy band gap of the crystal is found as $4.3 \mathrm{eV}$ and this asserts the suitability of the crystal for photonic and optical applications. The DTA curve shows that this compound undertakes a series of endothermic peaks in a wide temperature range $\left(114-1000^{\circ} \mathrm{C}\right)$. The mechanical studies indicate that the microhardness increases with the increase of load at lower values which can be attributed to the work hardening of the surface layers. The elastic stiffness constant $\left(\mathrm{C}_{11}\right)$ was calculated for different loads using Wooster's empirical formula. From Dielectric studies, the dielectric constant is a maximum at low frequency and decreases with increasing of frequency for the crystals. The vibrational spectroscopic study was carried out with a view to obtaining an insight into the structural aspects of optical nonlinearity of grown crystal. The photoluminescence study reveals that the grown crystal has a green emission property. The calculated hyperpolarizability value found to be nearly 2 times that of urea.

\section{REFERENCE}

1. V. Krishna Kumar, R. Nagalakshmi, Spectrochim. Acta A. Mol. Biomol. Spectrosc, 66, 924 (2007), DOI: $10.1016 /$ j.saa.2006.03.042 
2. P. Baskaran, M. Vimalan, P. Anandan, G. Bakiyaraj, K. Kirubavathi, S. G. Praveen and K. Selvaraju, Materials Research Express, 3, 035101 (2016), DOI: 10.1088/2053-1591/3/3/035101

3. Viji niraimathi, V. Aroulmoji and G. Rajarajan, American Journal of Materials Science and Engineering, 2, 36 (2014), DOI:10.12691/ajmse-2-3-2

4. T. Jayanalina, G. Rajarajan, K. Boopathi and K. Sreevani, Journal of Crystal Growth, 426, 9 (2015), DOI: $10.1016 /$ j.jcrysgro.2015.05.014

5. N. Senthilvelan, G. Rajarajan, S. Sivakumar, J. Elanchenzhiyan and A. Jegatheesan, Rasayan Journal of Chemistry, 10, 245 (2017), DOI: 10.7324/RJC.2017.1011566

6. P. Kumaresan, S. Moorthy Babu and P.M. Anbarasan, Optic. Mater., 30, 1361 (2008), DOI: $10.1016 /$ j.optmat.2007.07.002

7. N. Senthilvelan, G. Rajarajan, A. Jegatheesan, S. Sivakumar and J. Elanchenzhiyan, Rasayan Journal of Chemistry, 10, 218 (2017), DOI: 10.7324/RJC.2017.1011565

8. J. Zyss, R. Masse, M. Bagieu-Beucher, J. P. Levy, Adv. Mater., 5, 120 (1993), DOI: 10.1002/adma.19930050210

9. Y. Le Fur, M. Bagieu-Beucher, R. Masse, J.-F. Nicoud, J.-P. Levy, Chem. Mater., 8, 68 (1996), DOI: 10.1002/adma.19930050210

10. G.F. Lipscomb, A.F. Garito, R.S. Narang, J. Chem. Phys., 75, 1509 (1981), DOI: 10.1063/1.442157

11. B.F. Levine, C.G. Bethea, C.D. Thurmond, R.T. Lynch, J.L. Bernstein, J. Appl. Phys., 50, 2523 (1979), DOI: 10.1063/1.326248

12. J. Hernandez-Paredes, O. Hernandez-Negrete, R.C. Carrillo-Torres, R. Sanchez-Zeferino, A. DuarteMoller, M.E. Alvarez-Ramos, Spectrochim. Acta, Part A, 149, 240 (2015), DOI: $10.1016 /$ j.saa.2015.04.080

13. S.P. Karna, P.N. Prasad and M. Dupuis, J. Chem. Phys., 94, 1171 (1991), DOI: 10.1063/1.460024

14. A. Dey and G.R. Desiraju, Chem. Commun., 19, 2486 (2005), DOI: 10.1039/B502516H

15. J. Hernandez-Paredes, A.L. Olvera-Tapia, J.I. Arenas-García, H. H€opfl,H. Morales-Rojas, D. Herrera-Ruíz, A.I. Gonzaga-Morales, L. Rodríguez-Fragoso, Crystal Engineering Communication, 17, 5166 (2015), DOI: 10.1039/C4CE01934B

16. T.S. Thakur, R. Dubey, G.R. Desiraju, IUCrJ, 2, 159 (2015), DOI: 10.1107/S205225251500189X

17. D.Y. Curtin, I.C. Paul, Chem. Rev., 81, 525 (1981), DOI: 10.1021/cr00046a001

18. V. Arjunan, Mariusz K. Marchewka, A. Pietraszko, M. Kalaivani, Spectrochimica Acta Part A: Molecular and Biomolecular Spectroscopy, 97, 625 (2012), DOI: 10.1016/j.saa.2012.07.018

19. A. Jonie Varjula, C. Vesta, C. Justin Raj, S. Dinakaran, A. Ramanand, S. Jerome Das, Materials Letters, 61, 5053 (2007), DOI: 10.1016/j.matlet.2007.04.012

20. B. Neelakantaprasad, A. Jegatheesan, J. Murugan, V. Aroulmoji and G. Rajarajan, Asian Journal of Chemistry, 26, 176 (2014), DOI: 10.14233/ajchem.2014.15368

21. NP. Rajesh, V. Kannan, M. Ashok, K. Sivaji, P. Santhana Raghavan and P. Ramasamy, Journal of Crystal Growth, 262, 561 (2004), DOI: 10.1016/j.jcrysgro.2003.10.064

22. T Jayanalina, G Rajarajan, S Parthiban, and SC Mojumdar. Journal of Thermal Analysis and Calorimetry, 112, 1025 (2013), DOI: 10.1007/s10973-013-3058-7

23. T. Kanagasekaran, P. Mythili, P. Srinivasan, N. Shailesh Sharma, R. Gopalakrishnan, Materials Letters, 62, 2486 (2008), DOI: 10.1016/j.matlet.2007.12.039

24. A. Jegatheesan, G. Rajarajan, B. Ravi and B. Neelakantaprasad, Journal of Chemical and Pharmaceutical Research, 7, 2173 (2015)

25. W.A. Wooster, Rep. Phys. Phys., 16, 62 (1953), DOI: 10.1088/0034-4885/16/1/302

26. M. Narayan Bhat and SM Dharamaprakash, Journal of Crystal Growth, 242, 245 (2004), DOI: $10.1016 /$ S0022-0248(02)01327-1

27. R. Ezhil Vizhi and S. Kalainathan, Materials Letters, 62, $791 \quad$ (2008), DOI: $10.1016 /$ j.matlet.2007.06.083

28. A Jegatheesan, J Murugan, B Neelagantaprasad and G Rajarajan, International Journal of Computer Applications 53, 15 (2012), DOI: 10.5120/8408-2040 
RASĀYAN J. Chem.

Vol. 11 | No. 2 |915 - 928 | April - June | 2018

29. G. Senthil Murugan, N. Balamurugan and P. Ramasamy, Materials Letters, 62, 3087 (2008), DOI: $10.1016 /$ j.matlet.2008.01.137

30. SG. Bhat and SM. Dharaamaprakash, Materials Research Bulletin, 33, 833 (1998), DOI: $10.1016 /$ S0025-5408(98)00049-X

31. M.J. Frisch, G.W. Trucks, H.B. Schlegel, G.E. Scuseria, M.A. Robb, J.R. Cheeseman, J.A. Montgomery, Jr., T. Vreven, K.N. Kudin, J.C. Burant, J.M. Millam, S.S. Iyengar, J. Tomasi, V. Barone, B. Mennucci, M. Cossi, G. Scalmani, N. Rega, G.A. Petersson, H. Nakatsuji, M. Hada, M. Ehara, K. Toyota, R. Fukuda, J. Hasegawa, M. Ishida, T. Nakajima, Y. Honda, O. Kitao, H. Nakai, M. Klene, X. Li, J.E. Knox, H.P. Hratchian, J.B. Cross, C. Adamo, J. Jaramillo, R. Gomperts, R.E. Stratmann, O. Yazyev, A.J. Austin, R. Cammi, C. Pomelli, J.W. Ochterski, P.Y. Ayala, K. Morokuma, G.A. Voth, P. Salvador, J.J. Dannenberg, V.G. Zakrzewski, S. Dapprich, A.D. Daniels, M.C. Strain, O. Farkas, D.K. Malick, A.D. Rabuck, K. Raghavachari, J.B. Foresman, J.V. Ortiz, Q. Cui, A.G. Baboul, S. Clifford, J. Cioslowski, B.B. Stefanov, G. Liu, A. Liashenko, P. Piskorz, I. Komaromi, R.L. Martin, D.J. Fox, T. Keith, M.A. Al-Laham, C.Y. Peng, A. Nanayakkara, M. Challacombe, P.M.W.G. ill, B. Johnson, W. Chen, M. W. Wong, C. Gonzalez, J.A. Pople, Gaussian Inc, Wallingford CT, (2004)

32. A. Sudharsan, S. Seshadri, T. Gnanasambandan, R.R. Saravanan, Spectrochim.Acta A Mol. Biomol. Spectrosc., 131, 432 (2014), DOI: 10.1016/j.saa.2014.04.098

33. D.A. Kleinman, Physical. Review, 126, 1977 (1962)

[RJC-1655/2018] 